\title{
Socio-demographic determinants and prevalence of Tuberculosis knowledge in three slum populations of Uganda
}

\author{
Ekwaro A Obuku ${ }^{1,4^{*}}$, Clea Meynell1', Jemimah Kiboss-Kyeyune', Simon Blankley ${ }^{1}$, Christine Atuhairwe ${ }^{3}$, \\ Evelyn Nabankema ${ }^{3}$, Morris Lab ${ }^{2}$, Nikki Jeffrey ${ }^{2}$ and David Ndungutse ${ }^{3}$
}

\begin{abstract}
Background: Knowledge of tuberculosis has been shown to influence health seeking behaviour; and urban slum dwellers are at a higher risk of acquiring tuberculosis than the general population. The study aim was to assess knowledge of tuberculosis and identify the associated socio-demographic determinants, in order to inform tailored interventions for advocacy, communication and social mobilisation in three urban-slum communities of Uganda.

Methods: A cross-sectional survey of 1361 adults between April and October 2011. Data was analyzed by descriptive statistics. Adjusted odds ratios (aOR) and 95\% confidence intervals ( $95 \% \mathrm{Cl}$ ) of potential determinants of tuberculosis (TB) knowledge were estimated by multivariable ordinal logistic regression using Stata 11.2 software.

Results: We found low knowledge of TB cause (26.7\%); symptoms (46.8\%), transmission (54.3\%), prevention (34\%) and free treatment (35\%). Knowledge about TB treatment (69.4) and cure (85.1) was relatively high. Independent determinants of poor knowledge of TB in the multivariable analysis included (aOR, 95\% Cl) lack of formal education (0.56; $0.38-0.83, \mathrm{P}=0.004)$, unemployment $(0.67 ; 0.49-0.90, \mathrm{P}=0.010)$ and never testing for HIV $(0.69 ; 0.51-0.92$, $P<0.012)$. Whilst, older age $(1.73 ; 1.30-2.29, P<0.001)$ and residing in Lira $(2.02 ; 1.50-2.72, P<0.001)$ were independent determinants of higher knowledge of TB.

Conclusion: This study revealed deficiencies in the public health knowledge about TB symptoms, diagnosis and treatment among urban-slum dwellers in Uganda. Tuberculosis control programmes in similar settings should consider innovative strategies for TB education, advocacy, communication and social mobilisation to reach the youth, unemployed and less-educated; as well as those who have never tested for HIV.
\end{abstract}

Keywords: TB, Knowledge, Assessment, Slums, Advocacy, Communication and social mobilisation, Uganda

\section{Background}

World over, tuberculosis (TB) is a major cause of illness even though drugs to cure this disease have been available for the past 60 years [1,2]. Uganda is one of the 22 High Burden Countries with an incidence rate of 209 per 100,000 population [1] and a TB Case Detection Rate that has stagnated for the past 5 years, hovering between $37 \%$ and $61 \%[1,3]$ which signifies a need to go back to the drawing board.

\footnotetext{
*Correspondence: ekwaro@gmail.com

'International Medical Foundation, P.O Box 8177, Kampala, Uganda

${ }^{4}$ Joint Clinical Research Centre, P.O Box 10005, Kampala, Uganda

Full list of author information is available at the end of the article
}

Previous international studies involving different communities including TB patients in Low and Middle Income Countries [4-6] as well as in the developed world [7] suggest that lack of TB knowledge is an important barrier to $\mathrm{TB}$ diagnosis and treatment. And that TB knowledge varied by rural-urban setting, gender and education level. In Uganda, one qualitative study focused on people living in rural areas [8] whilst others investigated medical students $[9,10]$ and factors influencing treatment among TB patients [11-15]. To our knowledge no research on this topic has considered the urban slum population in Uganda.

The need to tackle the social determinants of TB has never been more urgent than today $[16,17]$. TB continues

\section{Biomed Central}


to cluster in disadvantaged groups including urban slum dwellers, who are more-often-than-not the poor and hungry [18-21]. Uganda's rapid population growth of $3.2 \%$ is one of the highest in the world [22], which coupled with migration from the rural areas [23] contributes to the mushrooming of urban slums and consequently a higher burden of TB in these settings. Yet, empowering people with TB and the affected communities is a key pillar of the Stop TB strategy that has not been sufficiently addressed in Uganda (Personal communication: Dr. Adatu Francis, National TB Programme Manager). The study aim was to assess knowledge of tuberculosis and identify the associated socio-demographic determinants, in order to inform tailored interventions for advocacy, communication and social mobilisation in three urban-slum communities of Uganda.

\section{Methods}

\section{Setting}

Three urban centres in Uganda at different levels of development namely Wobulenzi Town Council, Lira Municipal Council, and Makindye Division in Kampala City. Their 2010 projected populations were 23,100; 108,600 and 403,700 respectively. These three areas report a high annual burden of $\mathrm{TB}$ and have above-national HIV prevalence estimates $[22,24,25]$.

\section{Design and sampling procedures}

A cross-sectional survey was conducted between April and October 2011 as part of larger study assessing socio-economic vulnerabilities to TB in urban slums. A list of 58 villages was drawn based on the following criteria: settlements that were informal, unplanned, with limited social services, of high population density and low income. From this list, 35 villages (Wobulenzi $=10$; Lira $=10$; Kampala $=15)$ to be visited were randomly selected using open source software (OpenEpi version 2.3.3) [26]. The Field Officer (FO) liaised with Local Council chairmen to identify the "centre" and boundaries of the village. Once the study team assembled at the "centre", selection of the first respondent was done by spinning a bottle and following the direction where it pointed. Every third or fifth house was visited depending on the density of settlements to cover all four directions of the village. Respondents, one per house, who were 18 years or older and gave informed consent were eligible. Health workers were excluded.

\section{Data collection and management}

A survey questionnaire was designed to capture data on respondent demographics and TB knowledge with adaptations from the WHO guide on conducting surveys for advocacy-communication-and-social-mobilization (ACSM) for TB control [27]. The tool was translated into local languages (Luganda and Lango) and piloted by a mix of university students and members of the village-healthteams, fluent in both English and the local languages. This team received training in basic interview techniques prior to the study. They were supervised by experienced FOs to assure responsible conduct and data quality. Data was entered into Epi Info ${ }^{\mathrm{TM}}$ version 3.5.3 (Centres for Disease Control and Prevention, Atlanta, USA).

\section{Outcome measures and exposure variables}

The main outcome measure was the level of TB knowledge stratified as knowledge of cause, symptoms, transmission, risk groups, prevention, and treatment. Exposure variables included age, sex, marital status, educational level, employment, HIV-testing history, study site, distance from health unit and ownership of a communication device.

\section{Sample size estimation}

A sample size was independently estimated for each study area taking into account a maximum variability of 0.5 in the frequency of TB knowledge, \pm 0.05 precision, and $95 \%$ confidence interval. This yielded 430 participants per study site and 1290 in total after adjusting for a 0.1 proportion of persons not able to be contacted.

\section{Statistical considerations}

Data was analyzed using Intercooled Stata ${ }^{\mathrm{TM}}$ version 11.2 (StataCorp, College Station, Texas, USA). Demographic and outcome data was summarized into frequencies, percentages and measures of central tendency. Responses to the 10 questions about TB were scored (one point for correct and zero for incorrect) and categorized into $0-25,26-50,51-75$ and $76-$ 100 percent corresponding to poor, low, moderate and high TB knowledge respectively as a composite outcome. This distinguishes those with almost no knowledge at all (poor) from those with some knowledge about TB (low). The association between exposure variables and TB knowledge was explored by univariate analysis, with crude odds ratios (OR) and 95\% confidence intervals. Tests were two-sided and considered significant if $P<0.05$. Potential determinants of TB knowledge with $P<0.25$ at univariate level were included in a multivariable ordinal logistic regression model to estimate their adjusted odds ratios (aOR). Multiple imputations by chained equations was employed for sensitivity analysis of the missing data using the Stata command "ice" and "mim", assuming a Missing At Random mechanism. All missing baseline variables and the outcome, TB knowledge, were included to create five imputed data sets. 


\section{Ethical considerations}

This study was approved by the Mulago National Referral and Teaching Hospital Research Ethics Committee (MREC 501) and Uganda National Council for Science and Technology (SS 2571).

\section{Results}

\section{Socio demographic characteristics}

We interviewed 1361 eligible participants; 449 (33\%) in Wobulenzi, $470(34.5 \%)$ in Lira and $442(32.5 \%)$ in Makindye. Their median age was 30 years (IQR, 25 40). The majority of respondents were female (72.9\%); and $65.6 \%$ were married or cohabiting. A half $(48.9 \%)$ had attained secondary school, whilst $11 \%$ had never attended formal education. Most were self employed (63.7\%) with few having paid employment (18.5\%), whilst $78.5 \%$ said they had been tested for HIV before. Seventy percent lived within $1 \mathrm{~km}$ of a health facility; 70\% owned a Radio, $30.7 \%$ a TV and $37.4 \%$ a mobile phone (Table 1 ). The proportion of missing data was less than $5 \%$ and there were no statistically significant differences in baseline characteristics with the complete cases.

\section{Awareness of TB disease}

Many participants $(1139,83.7 \%)$ were aware of TB, initially from some form of contact with a TB patient

Table 1 Socio-demographic characteristics of respondents across the study areas

\begin{tabular}{|c|c|c|c|c|}
\hline Characteristic & All Study Areas & Wobulenzi & Lira & Makindye \\
\hline Age $^{\Phi}$ & $\mathrm{N}=1361(\%)$ & $n=442(\%)$ & $n=470(\%)$ & $n=449(\%)$ \\
\hline Median (IQR) & $30(25-40)$ & $32(25-44)$ & $30(25-40)$ & $29(24-36)$ \\
\hline $18-39$ & $987(73.8)$ & $298(67.6)$ & 331 (72.6) & $358(81.2)$ \\
\hline $40-59$ & $275(20.6)$ & $109(24.7)$ & $98(21.5)$ & $68(15.4)$ \\
\hline$\geq 60$ & $76(5.7)$ & $34(7.7)$ & $27(5.9)$ & $15(3.4)$ \\
\hline \multicolumn{5}{|l|}{ Gender $\$$} \\
\hline Female & $995(72.9)$ & $333(75.3)$ & $315(67)$ & $342(76.3)$ \\
\hline Male & $370(27.1)$ & $109(24.7)$ & $155(33)$ & $106(23.7)$ \\
\hline \multicolumn{5}{|l|}{ Marital Status ${ }^{\S}$} \\
\hline Married/Cohabiting & $892(65.6)$ & $297(67)$ & $281(60)$ & $314(69.9)$ \\
\hline Never Married & $245(18)$ & $64(14.5)$ & $104(22.2)$ & $77(17.2)$ \\
\hline Previously Married & $223(16.4)$ & $82(18.5)$ & $83(17.7)$ & $58(12.9)$ \\
\hline \multicolumn{5}{|l|}{ Education Level $^{\Phi}$} \\
\hline Secondary \& above & $664(48.9)$ & $211(47.7)$ & $195(41.6)$ & $258(57.6)$ \\
\hline Primary & $545(40.1)$ & $189(42.8)$ & $206(43.9)$ & $150(33.5)$ \\
\hline No School & $150(11)$ & $42(9.5)$ & $68(14.5)$ & $40(8.9)$ \\
\hline \multicolumn{5}{|l|}{ Source of Livelihood ${ }^{\Phi}$} \\
\hline Self Employed & $862(63.7)$ & $293(66.3)$ & $343(73.4)$ & $226(50.8)$ \\
\hline Employment Income & $251(18.5)$ & $45(10.2)$ & $77(16.5)$ & $129(29)$ \\
\hline None & $241(17.8)$ & $104(23.5)$ & $47(10.1)$ & $90(20.2)$ \\
\hline \multicolumn{5}{|l|}{ Ever done HIV test ${ }^{\Phi}$} \\
\hline Yes & $1053(78.5)$ & $278(63.9)$ & $390(84.2)$ & $385(86.7)$ \\
\hline No & $289(21.5)$ & $157(36.1)$ & $73(15.8)$ & 59 (13.3) \\
\hline \multicolumn{5}{|c|}{ Distance to Health Unit ${ }^{\Phi}$} \\
\hline$<1 \mathrm{~km}$ & $947(70)$ & $380(86.2)$ & $259(55.6)$ & $308(69.1)$ \\
\hline$>1 \mathrm{~km}$ & $406(30)$ & $61(13.8)$ & $207(44.4)$ & $138(30.9)$ \\
\hline \multicolumn{5}{|l|}{ Communication device* } \\
\hline Radio $^{\Phi}$ & $958(70.1)$ & $307(69.3)$ & $380(80.5)$ & $271(60.1)$ \\
\hline Mobile Phone ${ }^{\S}$ & $511(37.4)$ & $139(31.4)$ & $192(40.7)$ & $180(39.9)$ \\
\hline $\mathrm{TV}^{\Phi}$ & $419(30.7)$ & $108(24.4)$ & $71(15)$ & $240(53.2)$ \\
\hline Print Media§ & $39(2.9)$ & $4(0.9)$ & $17(3.6)$ & $18(4)$ \\
\hline
\end{tabular}

*Multiple responses question.

Differences across the study sites ${ }^{\S} p<0.01 \&{ }^{\Phi} p<0.001$.

${ }^{\mathrm{m}}$ Variables with missing data. 
(51.9\%) than from the media (29.3\%). Current TB information was commonly received through radio $(50 \%)$ followed by the formal health system (25.5\%). Those who said they had never heard of TB $(222,16.3 \%)$ were excluded from further analysis about TB knowledge.

\section{Knowledge of TB disease}

Few respondents identified a germ as the cause of $\mathrm{TB}$ (26.7\%); with smoking mentioned most commonly (37.1\%), whilst a third (27.7\%) did not know the cause of TB (Table 2). Coughing was the most frequently mentioned symptom reported as any cough $(46.4 \%)$ or

Table 2 Knowledge of Tuberculosis disease among slum dwellers in Uganda

\begin{tabular}{|c|c|c|c|c|c|}
\hline Knowledge Scale & Response & $\mathrm{N}=1139(\%)$ & Knowledge Scale & Response & $\mathrm{N}=1139(\%)$ \\
\hline \multirow[t]{7}{*}{ TB Cause } & Smoking & $423(37.1)$ & Who can get TB & $\Phi$ Anybody & $783(68.7)$ \\
\hline & $\Phi$ Germ & $304(26.7)$ & & PHAs & $223(19.5)$ \\
\hline & Alcohol & $227(19.9)$ & & Alcoholics & $145(12.7)$ \\
\hline & Malnutrition & $31(2.7)$ & & Drug Users & $116(10.2)$ \\
\hline & Witchcraft & $17(1.5)$ & & Poor & $56(5)$ \\
\hline & Other & $190(16.7)$ & & Prison History & $17(1.5)$ \\
\hline & Don't Know & $316(27.7)$ & & Homeless & $11(0.7)$ \\
\hline \multirow[t]{11}{*}{ TB Symptoms } & $\Phi$ Cough $>2$ weeks & $533(46.8)$ & & Other persons & $89(7.8)$ \\
\hline & Any Cough & $530(46.4)$ & ${ }^{*}$ TB Cure & $\Phi$ TB is Curable & $969(85.1)$ \\
\hline & Weight Loss & $380(33.4)$ & & TB is not Curable & $170(14.9)$ \\
\hline & Chest Pain & $314(27.6)$ & How is TB Cured & Ф Specific Drugs & $791(69.4)$ \\
\hline & Coughing up blood & $234(20.5)$ & & Treatment in Community & $200(17.6)$ \\
\hline & Fever & $185(16.2)$ & & Herbs & $38(3.3)$ \\
\hline & Shortness of Breath & $171(15)$ & & Home Rest Alone & $29(2.5)$ \\
\hline & Fever $>14$ days & $106(9.3)$ & & Prayer & $16(1.4)$ \\
\hline & Fatigue & $106(9.3)$ & & Other Cure & $23(2.0)$ \\
\hline & Other Symptoms & $61(5.4)$ & & Don't Know & $58(5.8)$ \\
\hline & Don't Know & $124(10.9)$ & Where is TB Cured & $\Phi$ Government Facilities & $911(80)$ \\
\hline \multirow[t]{7}{*}{ TB Transmission } & $\Phi$ Airborne & $618(54.3)$ & & Private Clinic & $167(14.7)$ \\
\hline & Sharing Utensils & $519(45.6)$ & & NGO/Church Facilities & $161(14.1)$ \\
\hline & Sharing Meals & $226(19.8)$ & & Traditional Healer & $45(4)$ \\
\hline & Shaking Hands & $74(6.5)$ & & Other Cure Place & $14(1.2)$ \\
\hline & Touching public items & $59(5.2)$ & ${ }^{*}$ How Long is $\mathbf{R x}$ & $<1$ month & $23(2.0)$ \\
\hline & Other routes & $102(8.9)$ & & $1-3$ months & $119(10.4)$ \\
\hline & Don't Know & $180(15.8)$ & & 3 - 6 months & $178(15.6)$ \\
\hline \multirow[t]{11}{*}{ TB Prevention } & Avoid Sharing Dishes & $489(42.9)$ & & Ф 6 - 8 months & $371(32.6)$ \\
\hline & $\Phi$ Cough Hygiene & $387(34)$ & & $>8$ months & $151(13.3)$ \\
\hline & Drugs & $281(24.7)$ & & Don't Know & $297(26.1)$ \\
\hline & Vaccination/BCG & $194(17)$ & ${ }^{*}$ Cost of TB Rx & $\Phi$ Free of charge & 399 (35) \\
\hline & Avoid Handshake & $98(8.6)$ & & Expensive & $367(32.2)$ \\
\hline & Washing Hands & $99(8.7)$ & & Affordable & $85(7.4)$ \\
\hline & Good Nutrition & $47(4.1)$ & & Don't Know & $288(25.3)$ \\
\hline & Closing Home Windows & $36(3.2)$ & & & \\
\hline & Prayer & $11(1)$ & & & \\
\hline & Other means & $141(12.4)$ & & & \\
\hline & Don't Know & $167(14.7)$ & & & \\
\hline
\end{tabular}

(1) Correct responses in bold.

*Non-multiple responses question.

$\S$ Individuals (51) missing baseline data $<5 \%$ in total.

Rx means treatment. 
cough $\geq 2$ weeks $(46.8 \%)$. Half the respondents $(54.3 \%)$ said TB transmission is airborne. The most frequently mentioned means of TB prevention was avoiding sharing dishes (42.9\%), followed by Cough hygiene (34\%), which was considered the correct response. Two thirds (68.7\%) said that although anybody can get TB, persons with HIV/AIDS (19.5\%) were at increased risk followed by alcoholics (12.7\%), drug users (10.2\%) and the poor (5\%).

Eighty five percent said $\mathrm{TB}$ is curable, using specific drugs (69.4\%). Although $80 \%$ knew TB treatment can be obtained from government facilities, only a third (35\%) were aware of free-of-charge TB treatment. In fact, $32.2 \%$ said $\mathrm{TB}$ treatment is expensive and a quarter (25.2\%) did not know whether TB treatment was provided free or at a fee. Remarkably, one third mentioned the correct $6-8$ months duration of TB treatment. Correct responses for TB knowledge are marked $(\phi)$ and in bold (Table 2).

\section{Determinants of TB knowledge score}

Age, gender, education level, employment status, HIV testing history, and distance from health unit; study site and ownership of a radio or a mobile phone were significantly associated with TB knowledge at univariate analysis (Table 3). In the multivariable ordinal logistic regression model (category, aOR, 95\% CI, P - value) older age $(40-59$ years; $1.73 ; 1.30-2.29, \mathrm{P}<0.001)$ and residence (Lira Town; 2.02; $1.50-2.72, \mathrm{P}<0.001$ ) were associated with higher TB knowledge scores. Whilst, lack of formal education $(0.56 ; 0.38-0.83, \mathrm{P}=0.004)$, unemployment $(0.67 ; 0.49-0.90, \mathrm{P}=0.010)$, never testing for $\operatorname{HIV}(0.69 ; 0.51-0.92, \mathrm{P}<0.012)$ remained statistically significant determinants of poor TB knowledge scores (Table 4). In this final model, the assumption of proportionality of odds was not violated when tested using the Brant test, $($ Chi square $=13.2 ; \mathrm{p}=0.982)$.

\section{Missing data}

The following baseline variables were missing: age (18), history of testing for HIV (11), distance (7), employment status (7), marital status (6), gender (1) and education level (1) totaling to $51(4.5 \%)$ incomplete cases. The imputed model was not adversely different from the complete cases analysis (Table 4).

\section{Discussion}

The TB incidence and mortality is declining globally except in Sub-Saharan Africa [1]. Reports from the Uganda National TB Control Programme (NTP) show that TB is more common in urban centres. Kampala city is estimated to have less than $10 \%$ of Uganda's population [22] yet accounts for a quarter of the country's tuberculosis burden [24]. This reflects the importance of socioeconomic determinants of TB [28].
In this study we report sub-optimal knowledge about TB in the general population of slum dwellers in three geographically distinct communities. We also identified that younger age, not having formal education; unemployment and not having tested for HIV were associated with a lower level of TB knowledge (poor), in the multivariable model. In Uganda, health information on TB and HIV/AIDs is disseminated through education talks in schools, places of work, media and through counseling before testing for HIV/AIDs. It is therefore not surprising that those with lack of education, unemployed, and never tested for HIV sero-status were associated with a lower level of TB knowledge. These groups of people are largely outside the formal TB information flow path way. Notably, except for differences in residence, these associations were marginal with adjusted Odds Ratios less than 2; hence we preferred to limit in-depth discussion of cause and effect.

Although TB awareness was high comprehension of the disease cause, symptoms, transmission and prevention was low. Invalid beliefs about the cause of TB are breeding grounds for myths and misconceptions resulting in stigma, social exclusion and can delay healthseeking behaviour in slum communities [29]. Health education efforts should thus demystify the TB disease process.

Smoking was the most mentioned cause of TB, and indeed $14.7 \%$ of men were current smokers (data not shown). The prevalence of smoking may even be higher among unemployed youth, which is a likely scenario in Ugandan slums. A recent meta-analysis [30] found an excess risk of TB infection, disease and mortality associated with smoking tobacco. This therefore presents a port of entry for joint TB and tobacco control in the study areas.

We found discordant knowledge between TB transmission and prevention. While the most frequent answer for TB transmission was "airborne through coughing" that for prevention was "not sharing eating utensils". Additionally, few participants understood BCG vaccination as an important TB prevention intervention, despite the high immunization coverage in Uganda. These inconsistencies depict gaps that can be addressed by tailored TB sensitization campaigns and health education in facilities.

Chronic cough, the prime symptom for TB, was known to less than half the respondents. Poor knowledge of TB symptoms may translate to delays in seeking care [29]. These results suggest the need for reinforcement of communication about chronic cough as the cardinal public-health TB symptom, which should trigger seeking healthcare from the formal sector by slum dwellers.

Knowledge of TB treatment and cure was relatively high particularly about using specific drugs from government health units. Nonetheless, lack of knowledge that 
Table 3 Univariate analysis of predictors of TB knowledge score among slum dwellers in Uganda

\begin{tabular}{|c|c|c|c|c|c|c|}
\hline \multirow[t]{2}{*}{ Variable } & \multicolumn{4}{|c|}{ TB Knowledge Score $(\mathrm{N}=1139)$} & \multirow[t]{3}{*}{ OR $(95 \% \mathrm{Cl})$} & \multirow[t]{3}{*}{ p-value } \\
\hline & Poor & Low & Moderate & High & & \\
\hline Total Study Population & $\overline{145(12.7)}$ & $\overline{428(37.6)}$ & $358(31.4)$ & $208(18.3)$ & & \\
\hline Age & & & & & & 0.004 \\
\hline $18-39$ & $113(75.5)$ & $328(72.6)$ & $247(67.6)$ & $141(73.8)$ & 1 & \\
\hline $40-59$ & $22(17.7)$ & $71(21.5)$ & $83(24.7)$ & $53(20.6)$ & $1.57(1.21-2.05)$ & \\
\hline$\geq 60$ & $9(7.3)$ & $21(5.9)$ & $21(7.7)$ & $11(5.7)$ & $1.13(0.71-1.80)$ & \\
\hline Gender & & & & & & 0.017 \\
\hline Female & $115(79.3)$ & $317(74.1)$ & $246(68.9)$ & $145(69.7)$ & 1 & \\
\hline Male & $430(20.7)$ & $111(25.9)$ & $111(31.1)$ & $63(30.1)$ & $1.33(1.05-1.68)$ & \\
\hline Marital Status & & & & & & 0.717 \\
\hline Married/Cohabiting & $95(66)$ & $287(67.4)$ & $227(63.4)$ & $144(70.2)$ & 1 & \\
\hline Never Married & $20(13.9)$ & $82(19.3)$ & $64(17.9)$ & $37(18)$ & $1.04(0.79-1.38)$ & \\
\hline Previously Married & $29(20.1)$ & $57(13.4)$ & $67(18.7)$ & $24(11.7)$ & $0.90(0.67-1.21)$ & \\
\hline Education Level & & & & & & 0.008 \\
\hline Secondary \& above & $60(41.4)$ & $223(52.2)$ & $181(50.6)$ & $122(58.7)$ & 1 & \\
\hline Primary & $59(40.7)$ & $161(37.7)$ & $137(38.3)$ & $73(35.1)$ & $0.82(0.66-1.04)$ & \\
\hline Did Not Attend School & $26(17.9)$ & $43(10.1)$ & $40(11.2)$ & $13(6.3)$ & $0.58(0.40-0.83)$ & \\
\hline Source of Livelihood & & & & & & $<0.001$ \\
\hline Self Employed & $79(54.5)$ & $262(61.5)$ & $232(65.2)$ & $134(65.3)$ & 1 & \\
\hline Employment Income & $26(17.9)$ & $77(18.1)$ & $74(20.8)$ & $49(23.9)$ & $1.17(0.90-1.52)$ & \\
\hline None & $40(27.6)$ & $87(20.4)$ & $50(14)$ & $22(10.7)$ & $0.61(0.47-0.79)$ & \\
\hline Ever done HIV test & & & & & & 0.001 \\
\hline Yes & $103(72.5)$ & $335(78.6)$ & $296(83.4)$ & $174(84.9)$ & 1 & \\
\hline No & $39(27.5)$ & $91(21.4)$ & $59(16.6)$ & $31(15.1)$ & $0.64(0.49-0.84)$ & \\
\hline Distance to Health Unit & & & & & & 0.014 \\
\hline$<1 \mathrm{~km}$ & $108(75)$ & $307(72.4)$ & $244(68.4)$ & $134(64.7)$ & 1 & \\
\hline$>1 \mathrm{~km}$ & $36(25)$ & 117 (27.6) & $113(31.6)$ & $73(35.3)$ & $1.34(1.06-1.69)$ & \\
\hline Study Site & & & & & & $<0.0001$ \\
\hline Wobulenzi & $61(42.1)$ & $153(35.8)$ & $104(29.1)$ & $56(26.9)$ & 1 & \\
\hline Lira & $23(15.9)$ & $107(25)$ & $142(39.7)$ & $91(43.4)$ & $2.84(2.22-3.64)$ & \\
\hline Makindye & $61(42.1)$ & $168(39.3)$ & $112(31.3)$ & $61(29.3)$ & $1.29(1.01-1.65)$ & \\
\hline \multicolumn{7}{|l|}{ Communication device } \\
\hline \multirow[t]{2}{*}{ Radio (YES) } & $93(64.1)$ & $294(68.7)$ & $269(75.1)$ & $159(76.4)$ & 1 & 0.002 \\
\hline & $52(35.9)$ & $134(31.3)$ & $89(24.9)$ & 49 (23.6) & $0.68(0.54-0.87)$ & \\
\hline \multirow[t]{2}{*}{ TV (NO) } & $104(71.7)$ & $282(65.9)$ & $252(70.4)$ & $133(63.9)$ & 1 & 0.524 \\
\hline & $41(28.3)$ & $146(34.1)$ & $106(29.6)$ & $75(36.1)$ & $1.08(0.87-1.33)$ & \\
\hline \multirow[t]{2}{*}{ Mobile Phone (NO) } & $96(66.2)$ & $268(62.6)$ & $224(62.6)$ & $110(52.9)$ & 1 & 0.019 \\
\hline & 49 (33.8) & $160(37.4)$ & $134(37.4)$ & $98(47.1)$ & $1.29(1.04-1.61)$ & \\
\hline
\end{tabular}

OR - Crude Odds Ratio; $\mathrm{Cl}$ - Confidence Interval; Level of significance $\mathrm{p}<0.05$.

SIndividuals (51) missing baseline data $<5 \%$ in total.

TB services are free is a potential barrier to seeking TB care. The low response about seeking TB treatment from traditional healers contradicts existing reports that $60 \%$ of Ugandans first visit local medicine men, before the formal health sector [31]. This finding may be limited to urban settings, or is a consequence of high awareness of TB cure from designated centres; or perhaps is an effect of social desirability bias.

Older respondents had higher TB knowledge scores, particularly the $40-59$ age category compared to the 
Table 4 Multivariate ordinal logistic regression analysis of predictors of TB knowledge score among slum dwellers in Uganda

\begin{tabular}{|c|c|c|c|c|c|c|}
\hline \multirow[t]{2}{*}{ Variable } & \multicolumn{3}{|c|}{ COMPLETE CASES $(n=1088)$} & \multicolumn{3}{|c|}{ IMPUTED $(n=1139)$} \\
\hline & aOR & $95 \% \mathrm{Cl}$ & p-value & aOR & $95 \% \mathrm{Cl}$ & p-value \\
\hline \multicolumn{7}{|l|}{ Age } \\
\hline $18-39$ & 1 & - & & 1 & - & \\
\hline $40-59$ & 1.73 & $1.30-2.29$ & $<0.001$ & 1.67 & $1.26-2.20$ & $<0.001$ \\
\hline$\geq 60$ & 1.46 & $0.89-2.40$ & 0.133 & 1.49 & $0.91-2.44$ & 0.113 \\
\hline \multicolumn{7}{|l|}{ Gender } \\
\hline Female & 1 & - & & 1 & - & \\
\hline Male & 1.06 & $0.83-1.33$ & 0.611 & 1.06 & $0.83-1.33$ & 0.611 \\
\hline \multicolumn{7}{|l|}{ Education Level } \\
\hline Secondary \& above & 1 & - & & 1 & - & \\
\hline Primary & 0.79 & $0.63-1.01$ & 0.065 & 0.82 & $0.64-1.03$ & 0.090 \\
\hline Did Not Attend School & 0.56 & $0.38-0.83$ & 0.004 & 0.54 & $0.37-0.79$ & 0.001 \\
\hline \multicolumn{7}{|l|}{ Source of Livelihood } \\
\hline Self Employed & 1 & - & & 1 & - & \\
\hline Employment Income & 1.22 & $0.91-1.64$ & 0.211 & 1.22 & $0.91-1.64$ & 0.174 \\
\hline None & 0.67 & $0.49-0.90$ & 0.010 & 0.65 & $0.48-0.88$ & 0.005 \\
\hline \multicolumn{7}{|l|}{ Ever done HIV test } \\
\hline Yes & 1 & - & & 1 & - & \\
\hline No & 0.69 & $0.51-0.92$ & 0.012 & 0.67 & $0.50-0.89$ & 0.006 \\
\hline \multicolumn{7}{|l|}{ Distance to Health Unit } \\
\hline$<1 \mathrm{~km}$ & 1 & - & & 1 & - & \\
\hline$>1 \mathrm{~km}$ & 1.16 & $0.90-1.49$ & 0.250 & 1.19 & $0.93-1.51$ & 0.171 \\
\hline \multicolumn{7}{|l|}{ Study Site } \\
\hline Wobulenzi & 1 & - & & 1 & - & \\
\hline Lira & 2.02 & $1.50-2.72$ & $<0.001$ & 1.95 & $1.46-2.61$ & $<0.001$ \\
\hline Makindye & 0.93 & $0.70-1.23$ & 0.611 & 0.92 & $0.70-1.22$ & 0.577 \\
\hline \multicolumn{7}{|l|}{ Communication device* } \\
\hline \multirow[t]{2}{*}{ Radio (YES) } & 1 & - & 0.192 & 1 & - & 0.125 \\
\hline & 0.85 & $0.66-1.09$ & & 0.82 & $0.64-1.05$ & \\
\hline \multirow[t]{2}{*}{ Mobile Phone (NO) } & 1 & - & 0.345 & 1 & - & 0.215 \\
\hline & 1.12 & $0.89-1.41$ & & 1.15 & $0.92-1.44$ & \\
\hline
\end{tabular}

aOR - Odds Ratio adjusted for all variables in the model; $\mathrm{Cl}$ - Confidence Interval; Level of significance $\mathrm{p}<0.05$.

Brant test Chi square $=13.2 ; \mathrm{p}=0.982$ for complete cases analysis.

Probability $>\mathrm{F} ;<0.0001$ for significant variables in imputed model.

Probability $>F ;=0.1768$ for non-significant variables in imputed model.

Probability $>\mathrm{F} ;<0.0001$ for all variables in imputed model.

younger adults. In two previous studies in resourceconstrained settings, older age was associated with earlier TB diagnosis health-seeking behavior [29]. It is possible that there was an age cohort effect in the $40-$ 59 age group, who could have had more repeated chances of reinforcing exposure to TB information than younger age groups. This implies efforts to educate the slum population about TB should consider messages that reach the younger generation.
Consistent with previous research [29,32], level of education explained disparities in TB knowledge scores. Those who had never attended formal education had poor knowledge of TB. This calls for innovative action to reach those with limited writing and reading skills through TB drama, verbal and pictorial messages as part of a comprehensive ACSM strategy. For example, utilizing sign posts or radio jingles to intensify $\mathrm{TB}$ awareness and prevention campaigns in locally spoken languages. 
Those without meaningful employment had significantly lower ТВ knowledge scores in the multivariable regression model. Indeed the interaction between poverty, ignorance and disease cannot be overemphasized making the unemployed a suitable target group for tailored TB health promotion interventions.

HIV testing was associated with a higher TB knowledge score. Since 2005 Uganda's Ministry of Health aggressively rolled out routine provider initiated HIV counseling \& testing [33] which could be responsible for the high proportion of respondents who had tested for HIV in our study. It is likely that persons with HIV testing history had better general health-seeking behavior and exposure to health information. This important finding presents an opportunity for joint action from the HIV side, that is, routinely screen for TB during HIV Counseling and Testing initiatives.

Differences in study site independently predicted knowledge about TB. Compared to Wobulenzi Town and Makindye in Kampala City, respondents in Lira $\mathrm{Mu}-$ nicipality had higher TB knowledge scores. This could explain the consistent better performance by Lira with above-target Case Detection and Treatment Success Rates over the past 5 years in contrast to Wobulenzi and Kampala [24]. The NTP in Lira consistently received TB-specific support from donor agencies towards strengthening community based TB care by engaging the sub-county health workers of the village-health-team. This further asserts the case for sustained financial support and community mobilisation.

Noteworthy, ownership of a communication device was not associated with TB knowledge in the multivariable model. Seventy percent of the respondents owned a radio, and half reportedly obtained TB information from radio. This may have implications on the nature or intensity of $\mathrm{TB}$ of messages being aired on radio, suggesting the current strategy requires re-evaluation. Additionally, up to two-fifths of the respondents owned a mobile cellphone yet this was not an independent determinant of TB knowledge probably due to under utilization of this service. Good acceptability has been reported on the use of electronic media for health messages [34] and could be brought on board to raise TB knowledge among urban-slum dwellers, since the mobile phone density in Uganda is projected to increase in the near future [35].

This study had limitations. We restricted sampling to extremely poor unplanned settlements which may not be representative of slums. In addition, those who reportedly never heard of TB were excluded from the final analysis. Consequently, knowledge of TB may have been overestimated, thus limiting the genaralisability of these results. However, we found a generally poor comprehension of TB suggesting that the picture could even be worse. We also enrolled more participants than originally anticipated, but decided to take advantage of the larger sample size. Potential biases arising from recall and socio-desirability were minimized by testing and adjusting the study tools a priori. Missing data was explored statistically and did not show significant impact on the overall findings. Finally, being a cross-sectional study the temporal relationship between certain exposures and TB knowledge remain unclear, for example HIV testing history.

\section{Conclusions}

Our survey identified deficiencies and determinants of the public health knowledge about $\mathrm{TB}$, among slum dwellers of Wobulenzi, Lira and Makindye urban centres in Uganda. Lack of awareness and knowledge about TB is a well described barrier to seeking TB diagnostic and treatment services. Innovative TB advocacy, communication and social mobilisation strategies should be considered and target the youth, less educated and unemployed; as well as who have never had an HIV test. Not least, National TB Programmes and the Stop TB partners in similar settings in low and middle income countries should take action towards integrated TB-tobacco and TB/HIV control.

\section{Abbreviations \\ ACSM: Advocacy communication and social mobilization; AIDS: Acquired Immunodeficiency Syndrome; aOR: Adjusted Odds Ratio; BCG: Bacille Calmette Guerin; Cl: Confidence Interval; FO: Field Officer; HIV: Human Immunodeficiency virus; NTP: National TB Programme; OR: Odds Ratio; TB: Tuberculosis; USA: United States of America; WHO: World Health Organization.}

\section{Competing interests}

The authors declare that they have no competing interests.

\section{Acknowledgements}

Special thanks to the field officers (Jimmy Pule, Clare Kwebiha, Nargis Shiraz, Ashley Berg and Saada Matovu), students, village health teams, local councils, respondents, Victoria Nankabirwa, Joan Nankabirwa, Achilles Katamba (Sen. Epidemiologists) and Agnes Kiragga (Sen. Biostatistician). Adatu-Engwau Francis, Ogang Elly Rossette, Okao Ben, Bwogi Ellis, Soita Apollo, Kalyesubula Robert (NTP staff) and members of the Uganda Stop TB Partnership who participated in the needs assessment planning workshop. This study was supported with a grant from Comic Relief, United Kingdom in partnership with Target TB, Brighton, United Kingdom, International Medical Foundation, Kampala, Uganda and International Health Sciences University, Kampala, Uganda.

EAO is a Research Scholar based at the JCRC Uganda, Uganda-Case Western Reserve University Research Collaboration, supported by the Fogarty International Clinical Research Scholars and Fellows Program at Vanderbilt University (R24 TW007988) and the American Relief and Recovery Act, Fogarty International Centre, National Institutes of Health, USA.

\section{Author details}

${ }^{1}$ International Medical Foundation, P.O Box 8177, Kampala, Uganda. ${ }^{2}$ Target TB, Refuge House, 49-50 North Street, Brighton BN1 1RH, United Kingdom. ${ }^{3}$ International Health Sciences University, P. O Box 7782, Kampala, Uganda.

${ }^{4}$ Joint Clinical Research Centre, P.O Box 10005, Kampala, Uganda.

\section{Authors' contributions}

Authors contributed to study conception (CM, ML), design and development $(E A O, C M, M L, J K, S B, E N, C A, N J \& D N)$, statistical data analysis (EAO, CA), initial draft manuscript (EAO), interpretation of the results and appraisal of 
the manuscript (CM, ML, JK, SB, EN, CA, NJ \& DN), and approved the final draft, (EAO, CM, ML, JK, SB, EN, CA, NJ \& DN).

Received: 5 February 2012 Accepted: 28 June 2012

Published: 23 July 2012

\section{References}

1. World Health Organization: WHO report 2011. Global tuberculosis control. Geneva, Switzerland: World Health Organisation; 2011. WHO/HTM/TB/ 2011.16, accessed January 2012

2. Daniels $M$, Hill $A B$ : Chemotherapy of pulmonary tuberculosis in young adults; an analysis of the combined results of three Medical Research Council Trials. BMJ 1952, 1:1162-1168.

3. World Health Organization: WHO report 2009. Global tuberculosis control. Geneva, Switzerland: World Health Organisation; 2009. WHO/HTM/TB/ 2009.411, accessed June 2010.

4. Liefoghee R, Michiels N, Habib S, Moran SB, De Muniyick A: Perceptions \& Social Consequences of Tuberculosis: A Focus Group Study of Tuberculosis Patients in Sialkot. Pakistan. Soc Sc Medicine 1995, 41(12):1685-1692.

5. Abebe G, Deribew A, Apers L, Woldemichael K, Shiffa J, Tesfaye M, Abdissa A, Deribie F, Jira C, Bezabih M, Aseffa A, Duchateau L, Colebunders R: Knowledge, Health Seeking Behavior and Perceived Stigma towards Tuberculosis among Tuberculosis Suspects in a Rural Community in Southwest Ethiopia. PLoS One 2010, 5(10):e13339. doi:10.1371/journal.pone.0013339, accessed April 2011.

6. Mushtaq MU, Shahid U, Abdullah HM, Saeed A, Omer F, Shad MA, Siddiqui AM, Akram J: Urban-rural inequities in knowledge, attitudes and practices regarding tuberculosis in two District of Pakistan's Punjab province. International Journal for Equity in Health 2011, 10:8. www.equityhealthj.com/cont ent/10/1/8, accessed April 2011

7. West EL, Gadkowski LB, Østbye T, Piedrahita C, Stout JE: Tuberculosis Knowledge, Attitudes, and Beliefs Among North Carolinians at Increased Risk of Infection. NC Med J January/February 2008, 69(1):14-20.

8. Buregyeya E, Kulane A, Colebunders A, Waija A, Kiguli J, Mayanja, Musoke PG, Pariyo G, Mitchell EM: Tuberculosis knowledge, attitudes and health-seeking behaviour in rural Uganda. Int J Tuberc Lung Dis 2011, 15(7):938-942.

9. Emili J, Norman GR, Upshur REG, Scott F, John KR, Schmuck ML: Knowledge and practices regarding tuberculosis: a survey of final-year medical students from Canada, India and Uganda. Medical Education 2001, 35:530-536

10. Emili J, Scott F, Upshur RE, Schmuck ML, John KR: Attitudes toward tuberculosis of final year medical students from Canada, India, and Uganda. Teach Learn Med 2002, 14(3):168-174.

11. Nuwaha F: Factors influencing completion of treatment among tuberculosis patients in Mbarara District, Uganda. East Afr Med J 1997 Nov, 74(11):690-693

12. Adatu F, Odeke R, Mugenyi M, Gargioni G, McCray E, Schneider E, Maher D: Implementation of the DOTS strategy for tuberculosis control in rural Kiboga District, Uganda, offering patients the option of treatment supervision in the community, 1998-1999. Int J Tuberc Lung Dis 2003, 7(9):S63-S71.

13. Katamba A, Neuhauser DB, Smyth KA, Adatu F, Katabira E, Whalen CC: Patients' perceived stigma associated with community-based directly observed therapy of tuberculosis in Uganda. East Afr Med J $2005 \mathrm{Jul}$, 82(7):337-342.

14. Amuha MG, Kutyabami P, Kitutu FE, Odoi-Adome R, Kalyango JN: Non-adherence to anti-TB drugs among TB/HIV co-infected patients in Mbarara Hospital Uganda: Prevalence and associated factors. Afr Health Sci 2009, 9(S1):8-15.

15. Mafigiri DK, Macgrath JW, Whalen CC: Task shifting for tuberculosis control: A qualitative study of community-based directly observed therapy in urban Uganda. Glob Public Health 2012, 7(3):270-284 [Epub 2011 Jun 1].

16. Hargreaves JR, Boccia D, Evans CA, Adato M, Petticrew M, Porter J: The Social Determinants of Tuberculosis: From Evidence to Action. Am J Public Health 2011, 101:654-662.

17. Rasanathan K, Sivasankara KA, Jaramillo E, Lönnroth E: The social determinants of health: key to global tuberculosis control. Int J Tuberc Lung Dis 2011, 15(6):S30-S36.
18. Guwatudde D, Zalwango S, Kamya RM, Debanne SM, Diaz MI, Okwera A, Mugerwa RD, King C, Whalen CC: Burden of tuberculosis in Kampala, Uganda. Bull World Health Organ 2003, 81:799-805

19. Sekandi JN, Neuhauser D, Smyth K, Whalen CC: Active case finding of undetected tuberculosis among chronic coughers in a slum setting in Kampala, Uganda. Int J Tuberc Lung Dis 2009 April, 13(4):508-513.

20. Jackson S, Sleigh AC, Wang GJ, Liu XL: Poverty and the economic effects of TB in rural China. Int J Tuberc Lung Dis 2006, 10(10):1104-1110.

21. Muniyandi M, Ramachandran R, Gopi GP, Chandrasekaran V, Subramani R, Sadacharam KP, Kumaran P, Santha T, Wares F, Narayanan PR: The prevalence of tuberculosis in different economic strata: a community survey from South India. Int J Tuberc Lung Dis 2007, 11(9):1042-1045.

22. Uganda Bureau of Statistics: The 2002 Uganda Population and Housing Census, Population Size and Distribution. Kampala: UBOS; 2006. www.ubos. org accessed April 2011.

23. United Nations Human Settlements Programme: Situation Analysis of Informal Settlements in Kampala, Cities Without Slums, Sub-Regional Programme for Eastern \& Southern Africa. UN-HABITAT: Nairobi, Kenya; 2006. HS/873/06E. http://www.unhabitat.org/pmss/accessed April 2011.

24. Uganda National Tuberculosis and Leprosy Programme: Ministry of Health, 2005 - 2010 Quarterly Reports. Kampala, Uganda: MoH; 2011.

25. Ministry of Health (MOH) [Uganda] and ORC Macro: Uganda HIV/AIDS Serobehavioral Survey 2004-2005. Calverton, Maryland, USA: Ministry of Health and ORC Macro; 2006. www.worldcat.org/. . ./uganda-hivaids-serobehavioural-survey, accessed January 2011

26. Dean AG, Sullivan KM, Soe MM: OpenEpi: Open Source Epidemiologic Statistics for Public Health, Version 2.3.1.: www. OpenEpi.com, accessed January 2011.

27. World Health Organisation: Advocacy, communication and social mobilization for TB control: a guide to developing knowledge, attitude and practice surveys. Geneva, Switzerland: World Health Organisation; 2008. WHO/HTM/STB/ 2008.46. whqlibdoc.who.int/ publications/2008/9789241596176_eng.pdf, accessed April 2011

28. Dye C, Lonnroth K, Jaramillo E, Williams BG, Raviglione M: Trends in tuberculosis incidence and their determinants in 134 countries. Bull World Health Organ 2009, 87(9):683-691.

29. Storla DG, Yimer S, Bjune G: A systematic review of delay in the diagnosis and treatment of tuberculosis. BMC Publ Health 2008, 8(1):15

30. Bates MN, Khalakdina A, Pai M, Chang L, Lessa F, Smith KR: Risk of Tuberculosis From Exposure to Tobacco Smoke: A Systematic Review and Meta-analysis. Arch Intern Med 2007, 167(4):335-342.

31. Government of Uganda: Ministry of Health. Health Sector Strategic Plan III. Kampala: MoH; 2010. 2010/11-2014/15 www.health.go.ug/docs/ HSSP_III_2010.pdf, accessed September 2010.

32. Lu S-H, Tian B-C, Kang X-P, Zhang W, Meng X-P, Zhang J-B, Lo SK: Public awareness of tuberculosis in China: a national survey of 69253 subjects. Int J Tuberc Lung Dis 2009, 13(12):1493-1499.

33. Government of Uganda: Ministry of Health. Uganda National Policy Guidelines for HIV Counseling and Testing. Kampala: MoH; 2005. www.who.int/hiv/pub/ guidelines/uganda_art.pdf, accessed September 2010.

34. Mitchell KJ, Bull S, Kiwanuka J, Ybarra ML: Cell phone usage among adolescents in Uganda: acceptability for relaying health information. Health Educ Res 2011, 26(5):770-781.

35. Uganda Communications Commission: 2009/10 Post and Telecommunications Market Review. Kampala: UCC; 2010. www.ucc.co.ug/ marketstatistics.php, accessed November 2011.

\section{doi:10.1186/1471-2458-12-536}

Cite this article as: Obuku et al:: Socio-demographic determinants and prevalence of Tuberculosis knowledge in three slum populations of Uganda. BMC Public Health 2012 12:536. 